1 Tsunoda and Takahashi: Chigger mites, vegetation and deer

2

3

4

5

6

7

8

9

10

11

12

13

14

15

16

17

18

19

20

21

22

23

24

25

26

27

28
Takashi Tsunoda

Laboratory of Vector Ecology and

Environment, Institute of Tropical

Medicine, Nagasaki University,

1-12-4 Sakamoto, Nagasaki

852-8523, Japan.

Phone: +8195 8197811

Fax: +81958197812

E-mail: tsunoda@nagasaki-u.ac.jp

\title{
Host-seeking behavior of trombiculid mites on vegetation in relation to sika deer
}

TAKASHI TSUNODA ${ }^{1,2,3}$, MAMORU TAKAHASHI $^{4}$

${ }^{1}$ Laboratory of Applied Entomology and Zoology, Faculty of Horticulture, Chiba University, 648 Matsudo, Chiba 271-8510, Japan.

${ }^{2}$ Current address; Laboratory of Vector Ecology and Environment, Institute of Tropical Medicine, Nagasaki University, 1-12-4 Sakamoto, Nagasaki 852-8523, Japan.

${ }^{3}$ Corresponding author, e-mail: tsunoda@nagasaki-u.ac.jp

${ }^{4}$ Department of Anesthesiology, Saitama Medical School; Moroyama-machi, Iruma-gun, Saitama 350-0495, Japan. 
29 ABSTRACT We collected larval trombiculid mites on vegetation monthly from 30 October 1997 to February 2000, and from the heads of sika deer culled in March 2003 31 in Boso Peninsula, central Japan. Two species of trombiculid mites, Neotrombicula 32 nogamii Takahashi, Takano, Misumi and Kikuchi and Leptotrombidium scutellare 33 Nagayo, Miyagawa, Mitamura and Tamiya occurred on vegetation. Peak numbers of $34 \quad$. nogamii were found in January and L. scutellare numbers peaked in November. 35 Both species were collected predominantly on the top of Sasa bamboo stems, where 36 they formed clusters, though $N$. nogamii preferred heights of $40-50 \mathrm{~cm}$. Furthermore, 37 N. nogamii and Walchia masoni (Asanuma and Saito) were collected from deer. These 38 findings indicate that vegetation is an important substrate for some trombiculid mites 39 awaiting hosts.

40

KEY WORDS chigger mite, host, aggregation, Leptotrombidium scutellare, 42 Neotrombicula nogamii. Walchia masoni 
Though scrub typhus is an endemic disease in Asia, the Pacific and the northeast coast of Australia, larvae of trombiculid mites are important vectors of the pathogenic rickettsia, Orientia tsutsugamushi (Traub and Wisseman 1974, Goddard 2000). Larval trombiculid mites are usually collected from the soil by Tullgren's funnel method (Suzuki 1973, Uchikawa and Kumada 1978, Uchikawa et al. 1986) and/or from captured small mammals (Tamiya 1962, Nadchatram 1970). However, some species are collected from mid- and large-sized mammals (Kellogg et al. 1971, Pung et al. 1994, Forrester et al. 1996).

Host location and successful attachment is critical for the survival and reproduction of parasites. Though most ixodid ticks climb vegetation, clinging to the tips of stems or branches where they wait for direct contact with hosts, the final resting height is a major determinant of host specificity (Sonenshine 1993). Therefore, it may be advantageous for trombiculid mites that are parasites of mid- and large-sized mammals to await hosts on vegetation.

The trombiculid mite, Neotrombicula nogamii Takahashi, Takano, Misumi and Kikuchi, is reported as an ectoparasite of sika deer, Cervus nippon Temminck (Tamiya 1962, Takahashi et al. 2008), but is not found on rodents. We investigated host-seeking behavior of $N$. nogamii and other trombiculid mites on vegetation and infestation on deer in Boso Peninsula, central Japan.

\section{Materials and Methods}

Sampling of mites on vegetation. Sampling of trombiculid mites was carried out monthly from October 1997 to February 2000. Research was conducted in a forest gap on a plateau in the southern part of Boso Peninsula (Fig. 1A), which was the same area for collection of ticks by (Tsunoda 2007). Chinquapin pine, Lithocarpus edulis, and sugi cedar, Cryptomeria japonica surrounded the gap. The study area was covered with underbrush consisting of a bamboo (Pteioblastus chino), sedge (Carex sp.), eulalia (Miscanthus sinensis), hound berry (Solanum nigrum), bird's tare (Vicia cracca), and kudzu-vine (Pueraria lobata). The study area of $12 \times 28 \mathrm{~m}$ was divided into 21 plots of $4 \times 4 \mathrm{~m}$ each (Fig. 1B). The plots were subdivided into 16 quadrats of $1 \times 1 \mathrm{~m}$ each. One quadrat was selected in every plot by using a random number table on each sampling date. Three plants were chosen according to the cover rate of plant in each quadrat, resulting in a maximum of 63 (= $3 \times 21)$ plants being chosen monthly. We recorded plant species, plant height, height and specific locale on the plant used by trombiculid mites, and the number of mites. Trombiculid mites found on plants were collected with a forceps between 1 p.m. to 5 p.m. Mites were mounted with Hoyer's 
media (Krantz 1978) and identified under a microscope in the laboratory (Sasa 1956, Takahashi and Misumi 2007).

Collection of mites from large- and mid-sized mammals. We inspected 24 head skins of sika deer, Cervus nippon, which had been culled in Boso Peninsula (Katsuura 8; Otaki 3; Kimitsu 5; Ichihara 3; Kamogawa 5) in March 2003 (Fig. 1). After deer were shot, the head skins were removed from the animals and kept in a freezer until inspection. We also inspected two Reeves's muntjac, Muntiacus reevesi Ogilby, which had been culled in Kamogawa, Boso Peninsula in October 2001 and two raccoon dog, Nyctereutes procyonoides Gray, which were road kill in November 1995 and January 1999.

Statistical analysis. Chi square analysis was used to compare the heights of trombiculid mite collection on plants. As expected frequencies of collected mites were $<5$ in a height class, we grouped the height classes at both tails with the adjacent classes to create classes of adequate size. Preference for specific plant locale was analyzed by Fisher's exact test. Stems were grouped with the stem top to create a class of adequate size. The maximum height of a plant where mites were collected was compared with a questing height by Wilcoxon's signed rank test. The number of trombiculid mites composing a cluster was compared by Wilcoxon's rank sum test with continuity correction. Two-way ANOVA was used to analyze the relationship between mite species and site where deer were culled. All statistical analysis was conducted by R software.

\section{Results}

Trombiculid mites on plants. Two species of trombiculid mites were found on plants (175 Leptotrombidium scutellare Nagayo, Miyagawa, Mitamura and Tamiya, 216 $N$. nogamii). Leptotrobidium scutellare appeared earlier in the year than $N$. nogamii (Fig. 2). The number of L. scutellare peaked in November and N. nogamii in January. Most mites were collected from a bamboo, P. chino (Fig. 3). Dead branches of $L$. edulis and C. japonica were preferred next to (29\% of L. scutellare, $9 \%$ of $N$. nogamii). L. scutellare was collected mostly at $20-29 \mathrm{~cm}$ height although $N$. nogamii was at 40-49cm height (Fig. 4). The maximum heights of plants where mites were collected were different from the questing height both in L. scutellare $(\mathrm{V}=0, p<0.05)$ and $N$. nogamii $(\mathrm{V}=276, p<0.01)$. There was a significant difference in height of collection between $L$. scutellare and $N$. nogamii $\left(\chi^{2}=105.12\right.$, d.f. $\left.=3, p<0.001\right)$. More N. nogamii preferred the tops of stems than did L. scutellare (Fisher's exact test, $p<0.001$ ) (Fig. 6). L. scutellare and N. nogamii formed a cluster of their own species, although nine $N$. 
116 nogamii were found singly. More L. scutellare joined a cluster than did $N$. nogamii $117 \quad(\mathrm{~W}=92.5, p<0.05)$ (Fig. 7).

118 Attachment of trombiculid mites on middle and large sized mammals.

119 Twenty-one of 24 deer were hosted either N. nogamii or Walchia masoni (Asanuma and

120 Saito). Both mites infested 11 deer. N. nogamii was found on 58\% of deer and $W$.

121 masoni on 75\%. The number of mites per deer head was $15.1 \pm 7.1$ for $N$. nogamii and

$12231.9 \pm 9.1$ for $W$. masoni. Species composition of mites was variable between cull sites

123 (Fig. 8). There was an interaction between mite species and sites ( $\mathrm{F}=2.617$, d.f. $=9$, 38,

$124 P=0.018)$.

125 Though $L$. scutellare was collected from the raccoon dog, W. masoni and $N$.

126 nogamii were not (Table 1). However, W. masoni was collected from Reeves's

127 muntjac, and one L. scutellare was also collected.

\section{Discussion}

130 Our results show that both $L$. scutellare and $N$. nogamii preferred bamboo, specifically the stem tops, though the tendency was stronger in N. nogamii compared to L. scutellare. As bamboo leaves are one of preferred foods for sika deer in Boso Peninsula (Asada and Ochiai 1996), this site preference would result in higher mite/host contact. Our results also show that free-living $N$. nogamii were collected largely at heights of 40 - 50 $\mathrm{cm}$. The height is similar to a species of tick, Haemaphysalis megaspinosa (Tsunoda and Mori 1995), that is a parasite of large mammals in Japan (Kitaoka et al. 1975). Furthermore, $N$. nogamii was collected from sika deer. These results suggest that $N$. nogamii awaits sika deer at a suitable site on plants.

On the contrary, we did not collect $L$. scutellare from sika deer. Our timing may have been too late for $L$. scutellare to be collected from sika deer, as mite numbers on vegetation peaked in November and deer-hunting season was February and March. In addition, L. scutellare may prefer small- and mid-size mammals (Sasa 1956, Tamiya 1962), instead of large mammals, as L. scutellare was collected from both raccoon dog and Reeves's muntjac.

In three species of trombiculid mites we studied, only $L$. scutellare can transmit the tsutsugamushi pathogen in Japan. As the main host of the mite was thought to be rodents, unfed larvae were considered to transmit the pathogen to humans when they sit on the ground. However, our results suggest that $L$. scutellare can attack walking humans by contact with plants.

Some species of Leptotrombidium larvae tend to form a cluster close to the soil surface (Gentry et al. 1963). Cluster formation of those mites may result from egg 
152 clusters from the same female. Though L. scutellare is known to form clusters on 153 twigs and small rocks on the ground, this height is limited to within $10 \mathrm{~cm}$ of the ground 154 (Ueno et al. 1955). However, our results showed that many L. scutellare were 155 collected above $20 \mathrm{~cm}$, which may increase the opportunity to attach mid-sized mammals. Although we did not collect free-living W. masoni on vegetation, this species is suspected to cluster, based on sampling by Tullgren's funnel method (Uchikawa and Kumada 1978).

Since they form clusters, the spatial distribution of trombiculid mites is highly clumped, referred to as a 'mite island' (Traub and Wisseman 1974). Our results showed that $N$. nogamii and L. scutellare formed some clusters on plants. Sasa (1956) suggests that free-living larvae of trombiculid mites reduce the surface area of evaporation by forming a colony, i.e. cluster. Moisture retention by clustering has been demonstrated in adult American house dust mites, Dermatophagoides farinae Hughes (Glass et al. 1998). It is found that attached trombiculid mites tend to be closely grouped in clusters on the host with the mites all in the same degree of engorgement, indicating simultaneous attachment (Gentry et al.). Sasa (1956) also suggests that tight grouping of trombiculid mites by formation of a cluster increases the opportunity for greater number to parasitize simultaneously. Further studies are needed on clustering behavior so that the adaptive value can be understood.

\section{Acknowledgements}

We appreciate Keiji Ochiai and Takashi Ishihara for their collaboration in the collection of mites from deer. I would like to acknowledge Hiroshi Amano for his valuable support for collection of mites.

\section{Reference Cited}

Asada, M., and K. Ochiai. 1996. Food habits of sika deer on the Boso Peninsula, central Japan. Ecological Research 11: 89-95.

\section{Forrester, D. J., G. S. McLaughlin, S. R. Telford, Jr., G. W. Foster, and J. W.} McCown. 1996. Ectoparasites (Acari, Mallophaga, Anoplura, Diptera) of white-tailed deer, Odocoileus virginianus, from southern Florida. Journal of medical entomology 33: 96-101.

Gentry, J. W., C. S. Yueh, and P. O. Wah. 1963. Preliminary Observations on Leptotrombidium (Leptotrombidium) akamushi and Leptotrombidium (Leptotrombidium) deliensis in Their Natural Habitat in Malaya: (Acarina: 
Trombiculidae). American journal of hygiene 78: 181-190.

Glass, E. V., J. A. Yoder, and G. R. Needham. 1998. Clusteringt reduces water loss by adult American house dust mites Dermatophagoides farinae (Acari: Pyroglyphidae). Exp. Appl. Acarol. 22: 31-37.

Goddard, J. 2000. Infectious Diseases and Arthropods, Humana Press, Totowa, New Jersey.

Kellogg, F. E., T. P. Kistner, R. K. Strickland, and R. R. Gerrish. 1971. Arthropod parasites collected from white-tailed deer. Journal of medical entomology 8: 495-498.

Kitaoka, S., T. Morii, and K. Fujisaki. 1975. Consideration on the grazing cattle-tick relationship in Japan, with special reference to wild mammals and the deer-tick ecosystem in the Tanzawa Mountains. . Bull. Nat. Inst. Anim. Hlth. 70: 35-42.

Krantz, G. W. 1978. A Manual of Acarology, 2nd edn., Oregon State University, Oregon.

Nadchatram, M. 1970. Correlation of habitat, environment and color of chiggers, and their potential significance in the epidemiology of scrub typhus in Malaya (Prostigmata: Trombiculidae). Journal of medical entomology 7: 131-144.

Pung, O. J., L. A. Durden, C. W. Banks, and D. N. Jones. 1994. Ectoparasites of opossums and raccoons in southeastern Georgia. Journal of medical entomology 31: 915-919.

Sasa, M. 1956. Tsutsugamushi and Tsutsugamushi Disease, Igakushoin Ltd., Tokyo.

Sonenshine, D. E. 1993. Biology of Ticks. Vol. 2, vol. 2, Oxford University Press, Oxford.

Suzuki, H. 1973. Reports of medico-zoological investigations in the Nansei Islands. Part 1. The Trombiculid fauna of southern Amami-Oshima. . Jap. J. Sanit. Zool. 24: 135-142.

Takahashi, M., and H. Misumi. 2007. Key of larval trombiculidmites in Japan., pp. 277-294. In O. C. o. SADI (ed.), Acari and Emerging/Reemerging Infectious Diseases. Zenkoku Noson Kyoiku Kyokai Publishing Co. Ltd., Tokyo.

Takahashi, M., A. Takano, H. Misumi, and H. Kikuchi. 2008. Neotrombicula nogamii (Acari: Trombiculidae): A new species of chigger mite collected from Japanese deer, Cervus nippon Temminck, 1838 (Artiodactyla: Cervudae), in Japan. Acarologia 48: 55-59.

Tamiya, T. 1962. Recent Advances in Studies of Tsutsugamushi Disease in Japan Medical Culture Inc., Tokyo.

Traub, R., and C. L. Wisseman, Jr. 1974. The ecology of chigger-borne rickettsiosis 
(scrub typhus). Journal of medical entomology 11: 237-303.

Tsunoda, T. 2007. Seasonal Change in Habitat Use by Haemaphysalis longicornis (Acari: Ixodidae): Plant, Litter, and Soil. Journal of medical entomology 44: 575-579.

Tsunoda, T., and K. Mori. 1995. Heights of attachment to host in Haemaphysalis megaspinosa Saito and H. longicornis Neumann (Metastigmata: Ixodidae). Jap. J. Sanit. Zool. 46: 381-385.

Uchikawa, K., and N. Kumada. 1978. Studies on tsutsugamushi by Tullgren's funnel method. 2. Dependence on environment and seasonal fluctuation of tsutsugamushi. Jap. J. Sanit. Zool. 38: 323-332.

Uchikawa, K., N. Kumada, A. Taguchi, T. Nakatsuka, and A. Fukuda. 1986. Studies on tsutsugamushi by Tullgren's funnel method. 1. Evaluation of the method and distribution of Leptotrombidium pallidum in the residential areas. Jap. J. Sanit. Zool. 37: 363-370.

Ueno, Y., H. Tanaka, and M. Sasa. 1955. Notes on the mass-appearance phenomenon of Trombicula scutellaris larvae in Hachijo Island, and their mode of attaching 
244 Fig. 1. Map of study sites. (A) The study site on Boso Peninsula, central Japan. 245 Numbers show study sites in which deer were culled. Open star indicates the study 246 site for collection of trombiculid mites on vegetation. (B) Hierarchical sampling 247 design of the study site for collection of the mites.

249 Fig. 2. Seasonal abundance of $L$. scutellare and N. nogamii on plants from October 1997 to February 2000.

Fig. 3. Plant preference of two species of trombiculid mites, L. scutellare and $N$. nogamii. Number of the mites are shown on the top of graph.

Fig. 4. Height of trombiculid mites collected on plants. (A) L. scutellare, (B) N. nogamii.

Fig. 5. The maximum height and questing height of plants in which mites were collected. (A) L. scutellare, (B) N. nogamii.

Fig. 6. Parts of plants preferred by trombiculid mites.

Fig. 7. Number of trombiculid mites composing a cluster.

Fig. 8. Number of trombiculid mites, L. scutellare and W. masoni collected from sika deer captured in Katsuura, Otaki, Kimitsu, Kamogawa, and Ichihara. 
Table 1. Trombiculid mites collected from raccoon dog, $N$. procyonoides Gray, and Reeves's muntjac, $M$. reevesi Ogilby

270

\begin{tabular}{lllcc}
\hline \hline Host & Date & Site & No. L. scutellare & No. W. masonii \\
\hline N. procyonoides & Nov 1995 & Otaki & 51 & 0 \\
N. procyonoides & Jan 1999 & Kamogawa & 90 & 0 \\
$M$. reevesi & Oct 2001 & Kamogawa & 1 & 11 \\
$M$. reevesi & Oct 2001 & Kamogawa & 0 & 22 \\
$M$. reevesi & Oct 2001 & Kamogawa & 0 & 0 \\
$M$. reevesi & Oct 2001 & Kamogawa & 0 & 0 \\
\hline
\end{tabular}


Fig. 1.

(A)

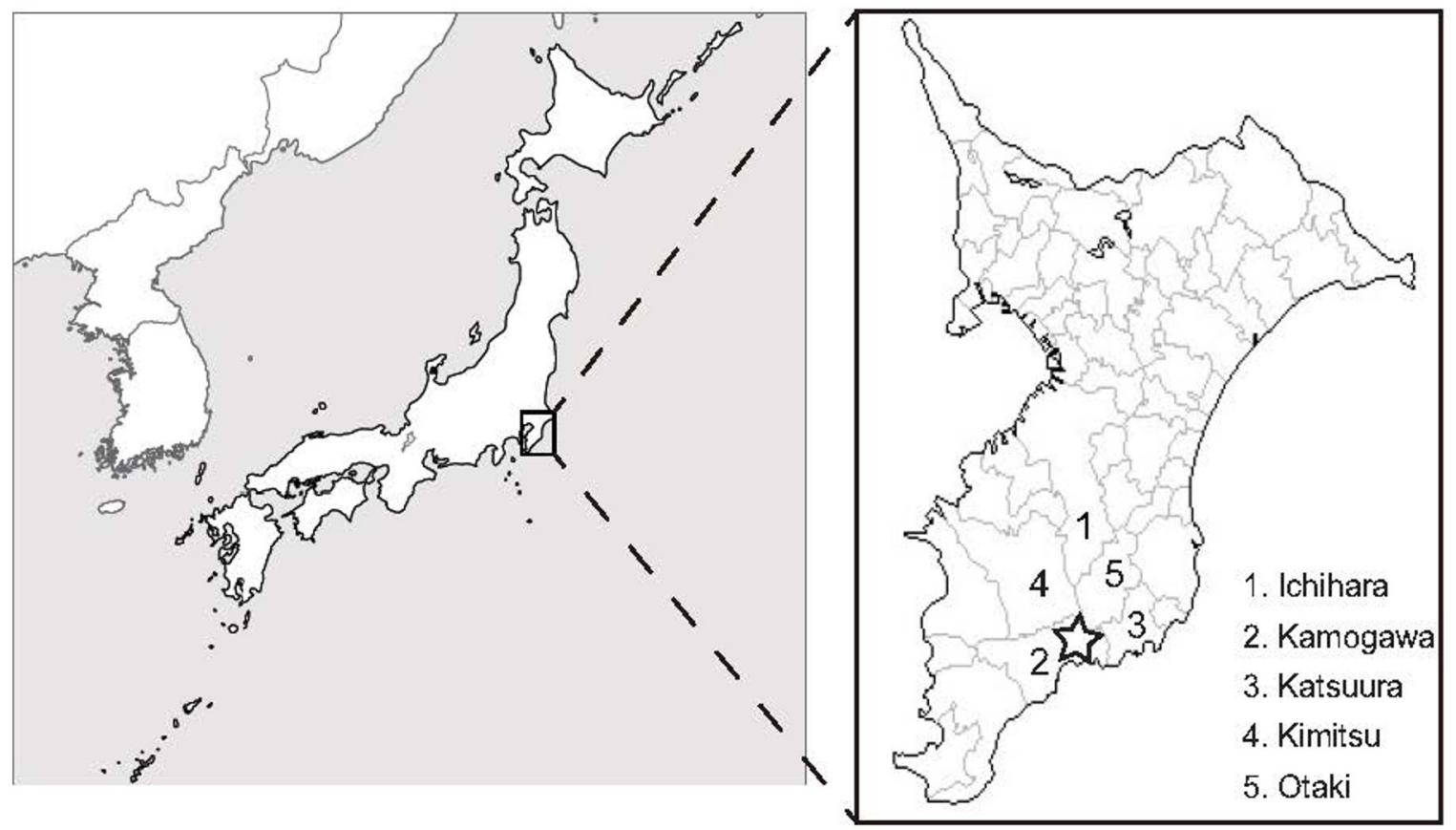

(B)

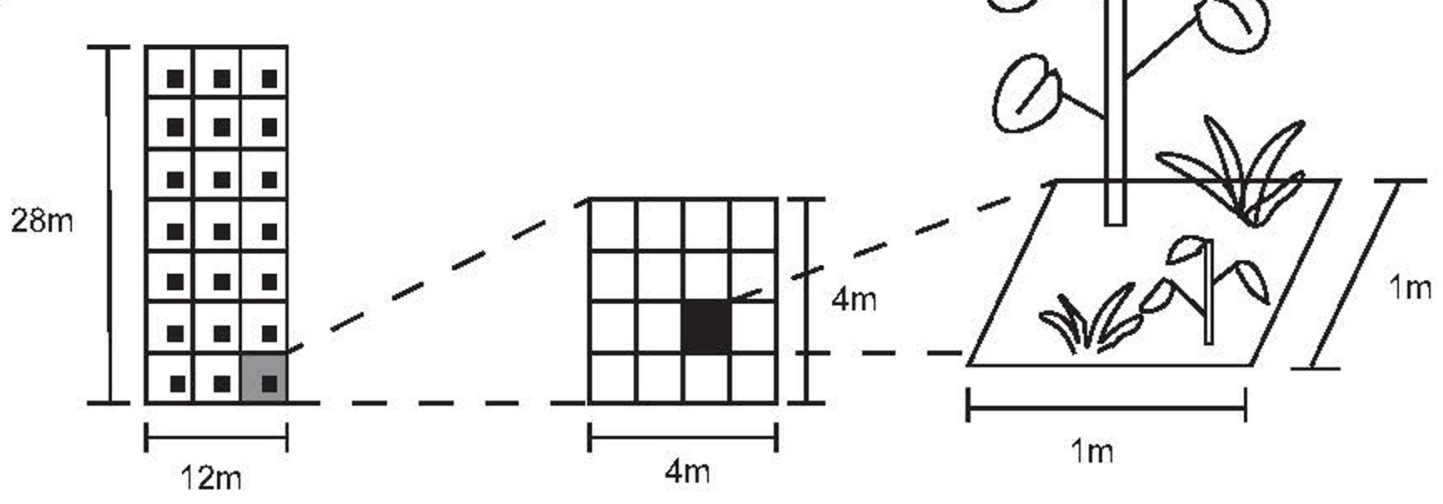


Fig. 2.

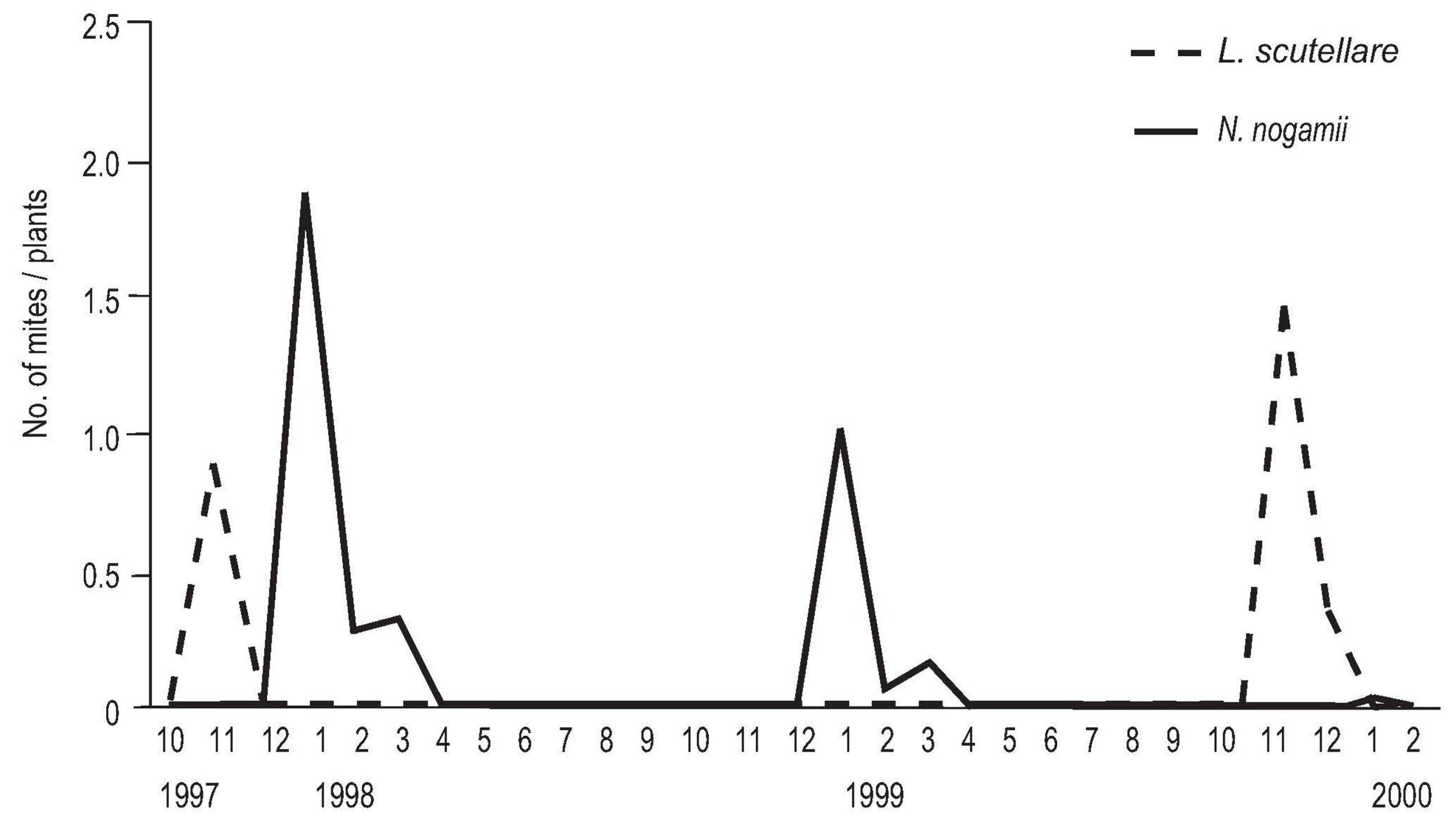


Fig. 3.

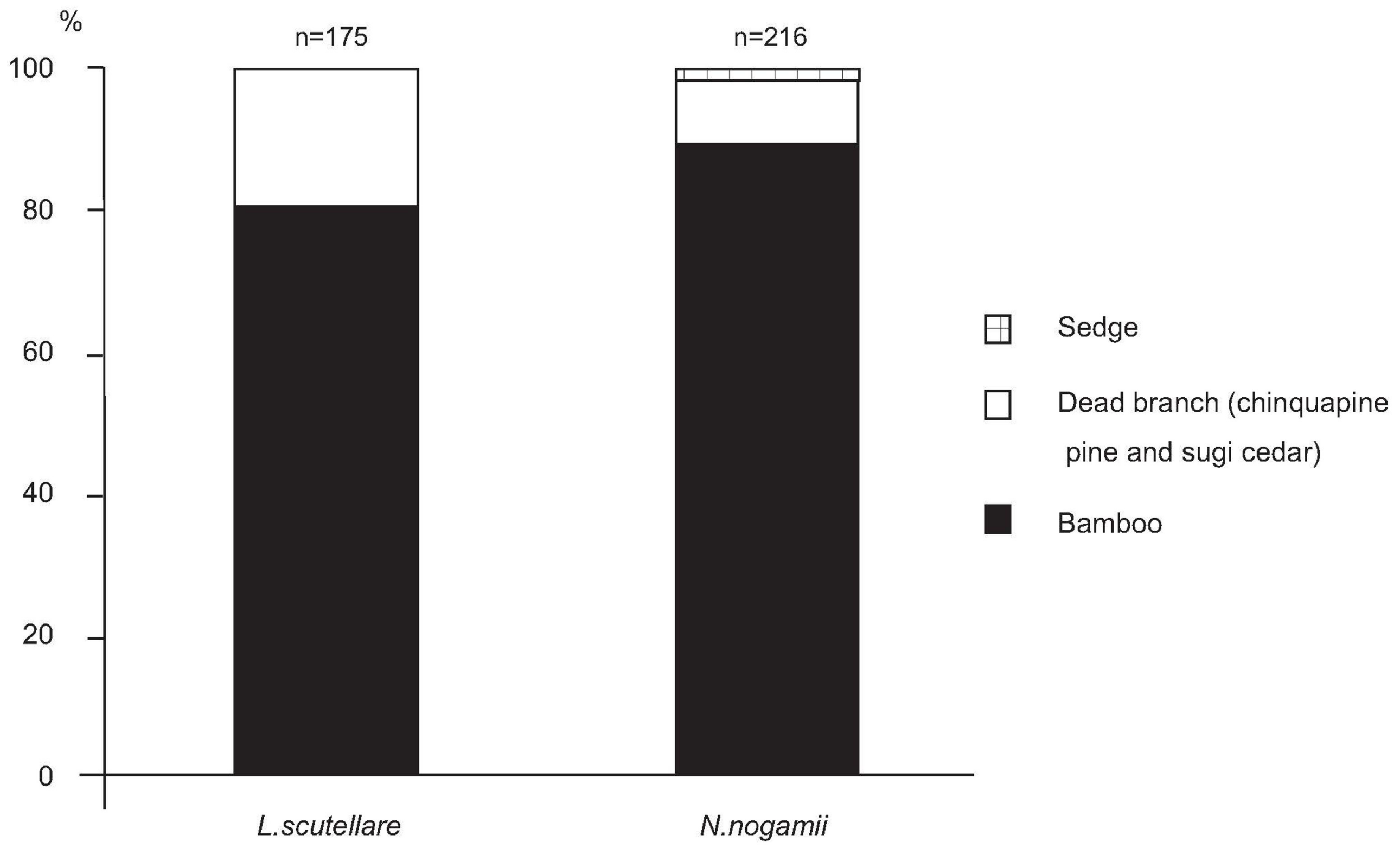


Fig. 4.

(A)

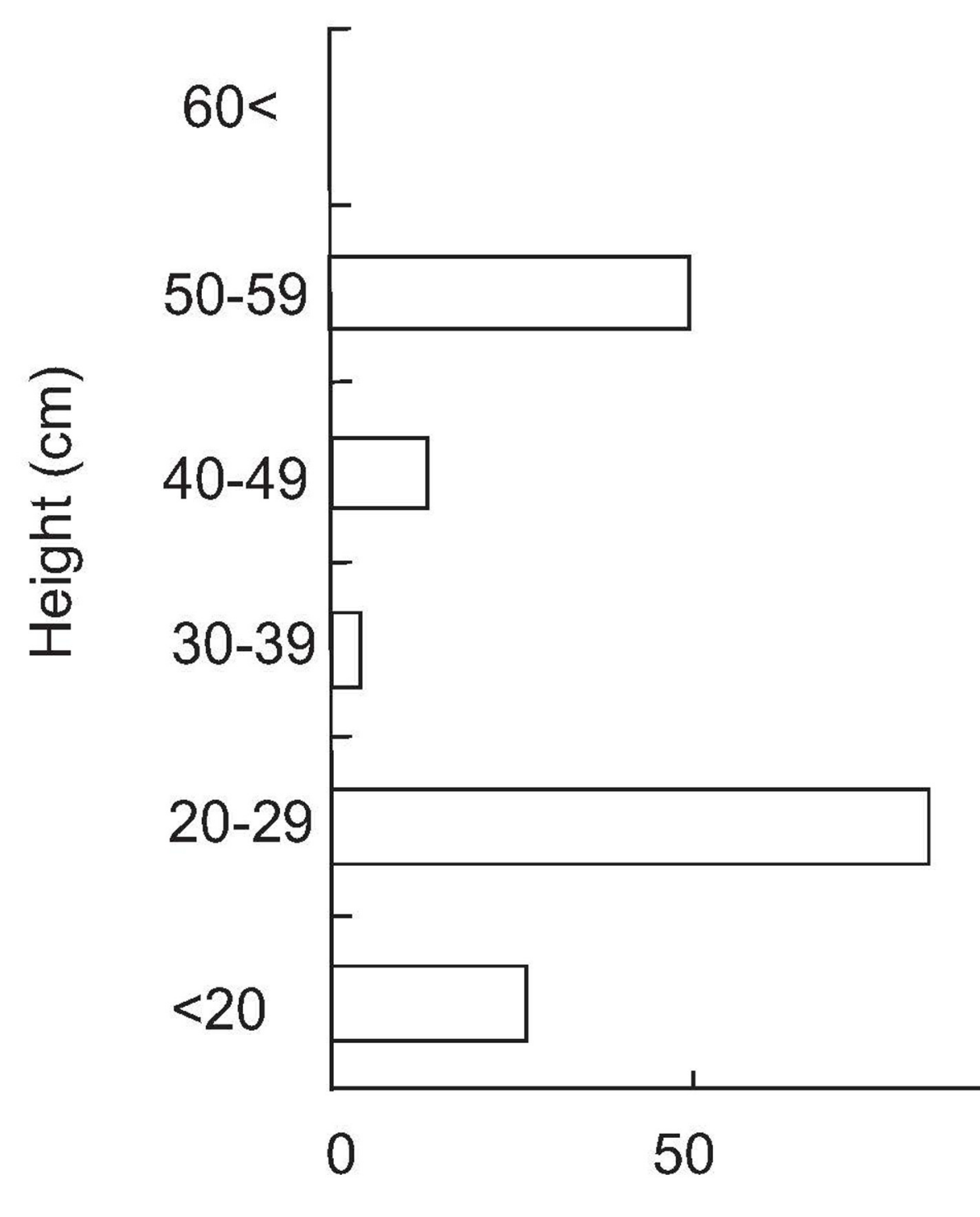

(B)

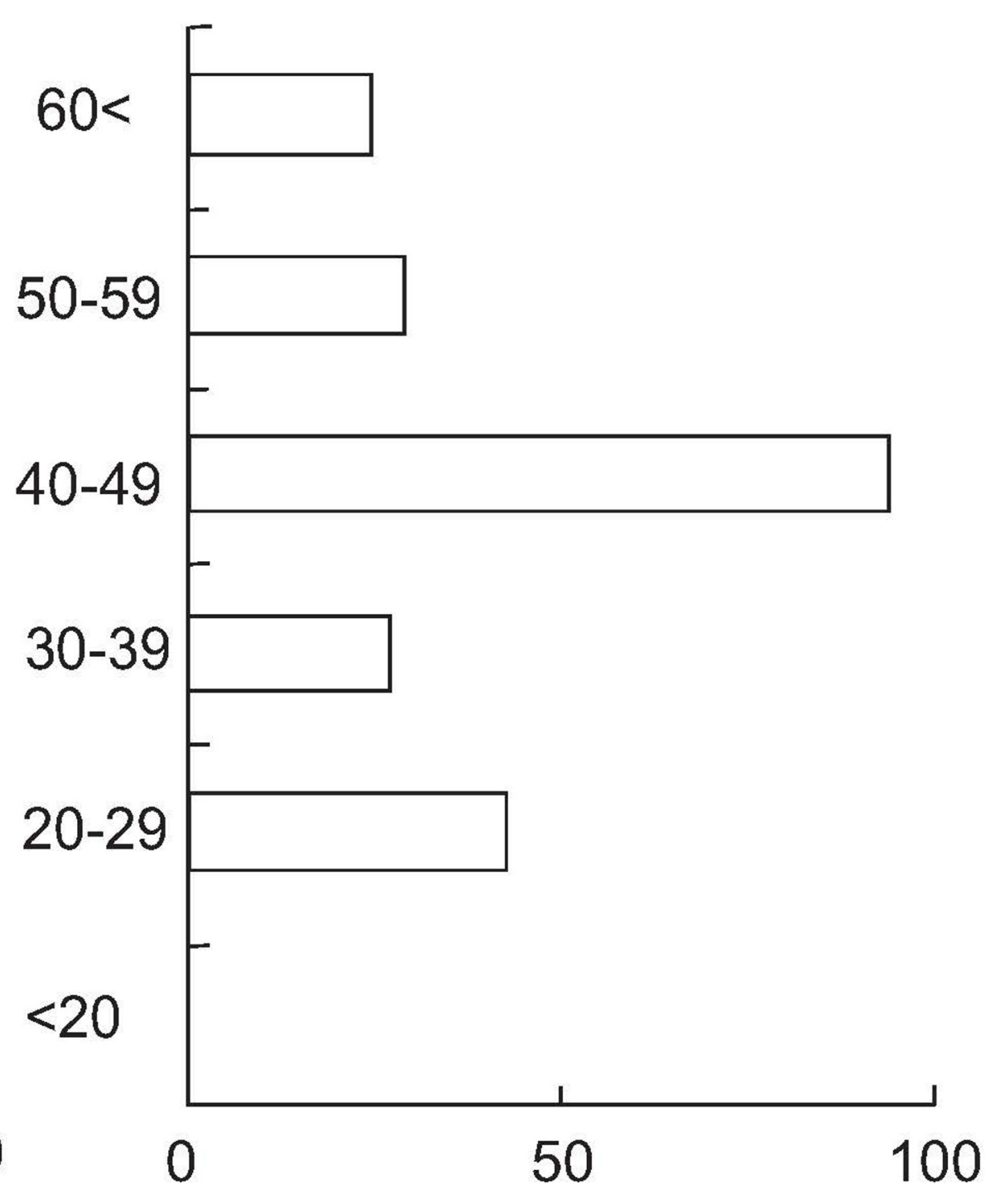

Number of mites 
Fig. 5.

A) L. scutellare

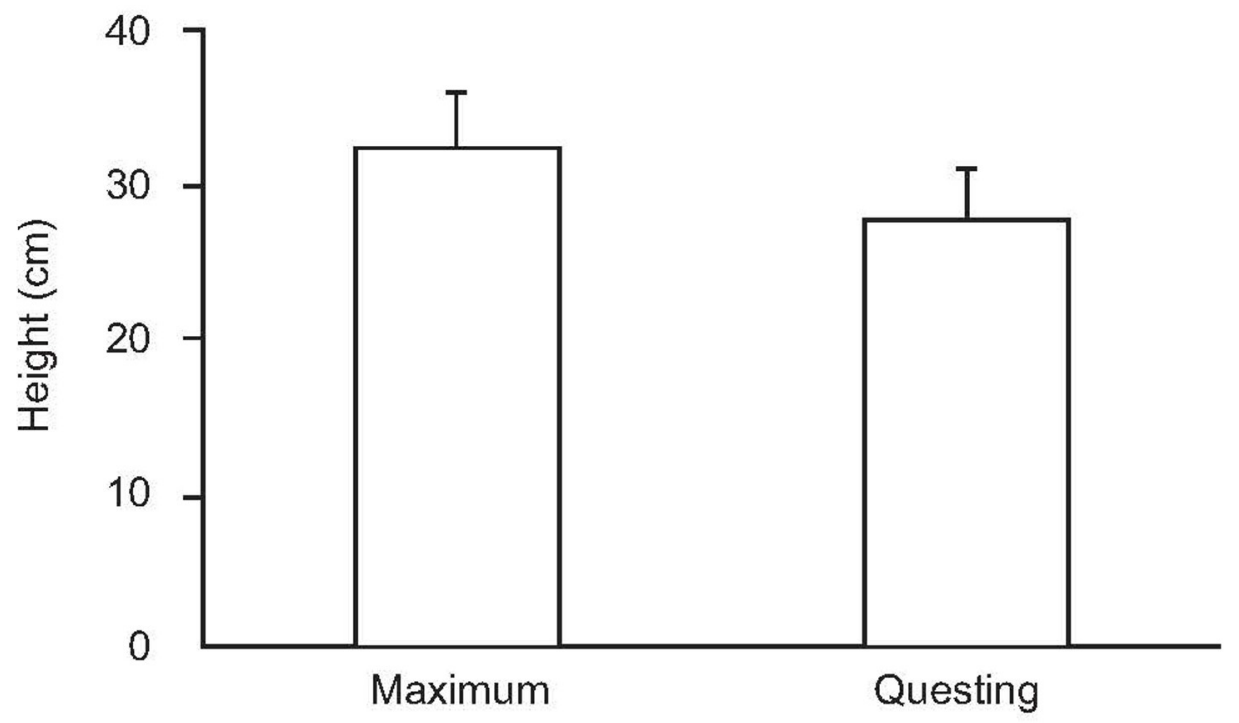

B) N. nogamii

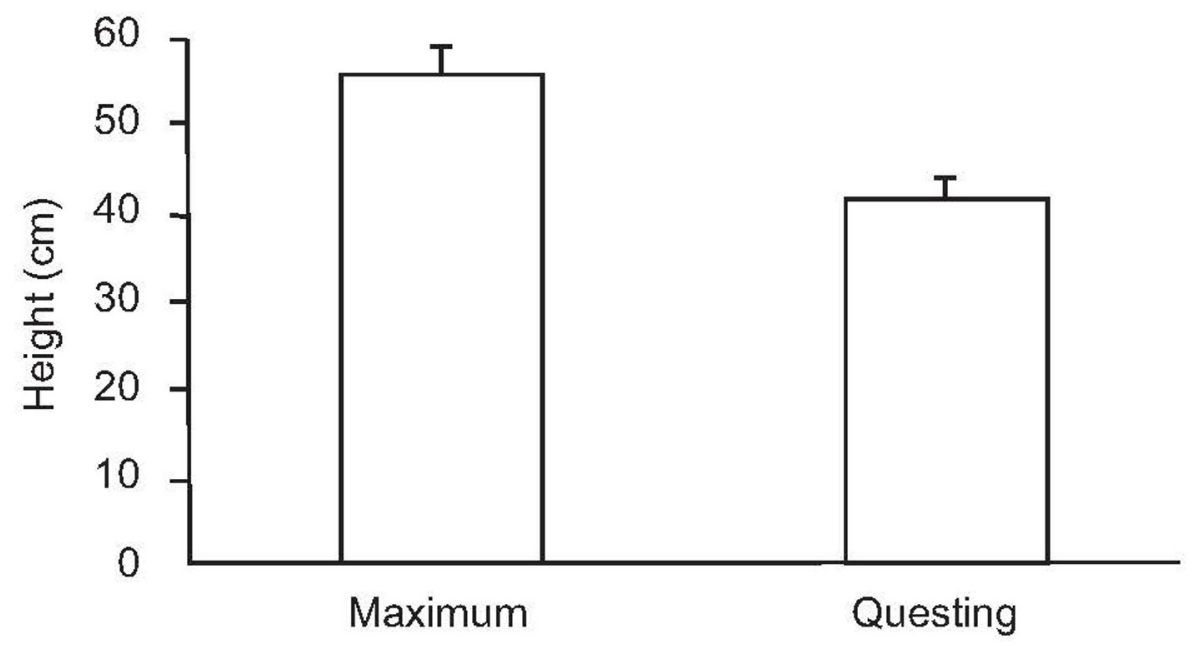


Fig. 6.

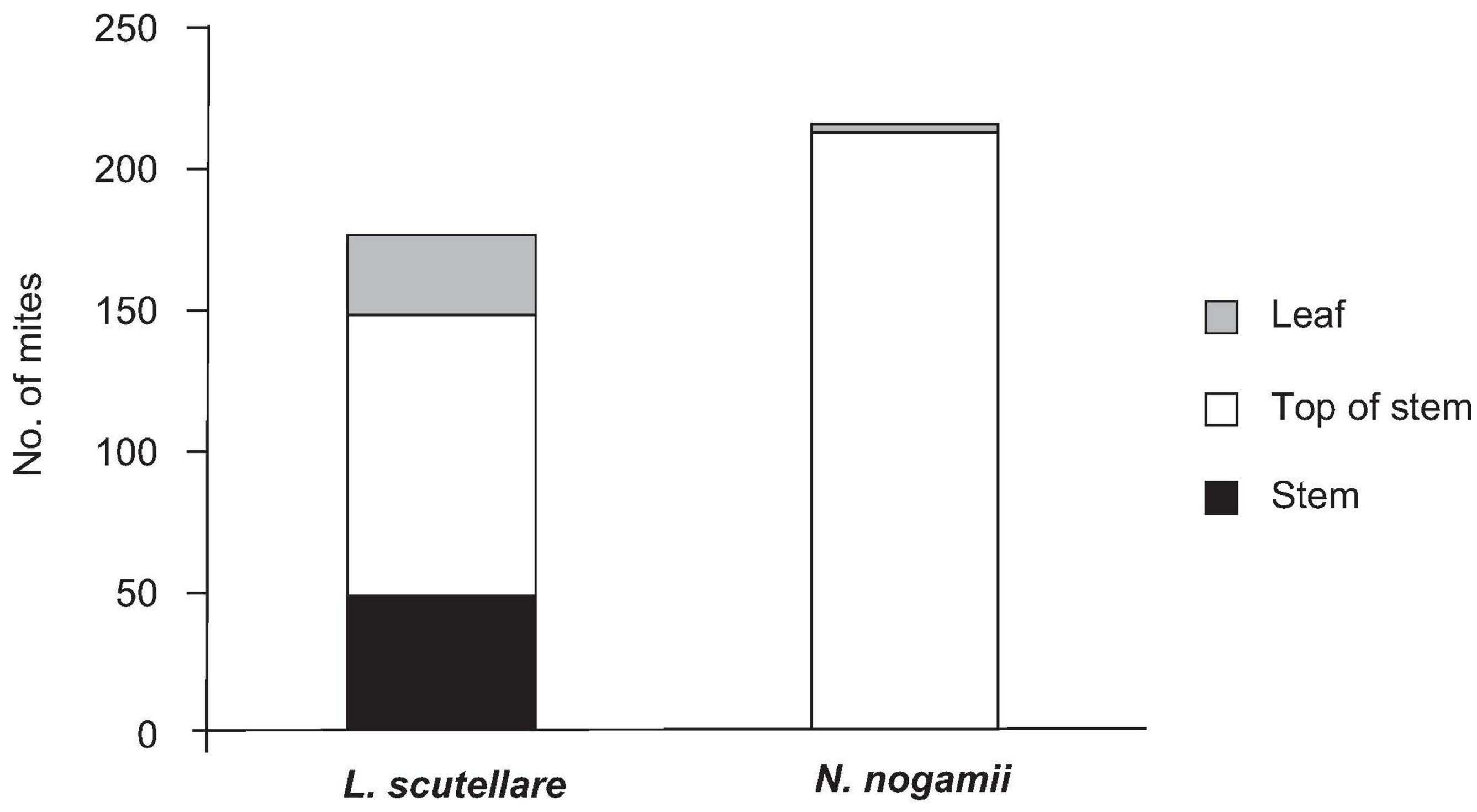


Fig. 7.

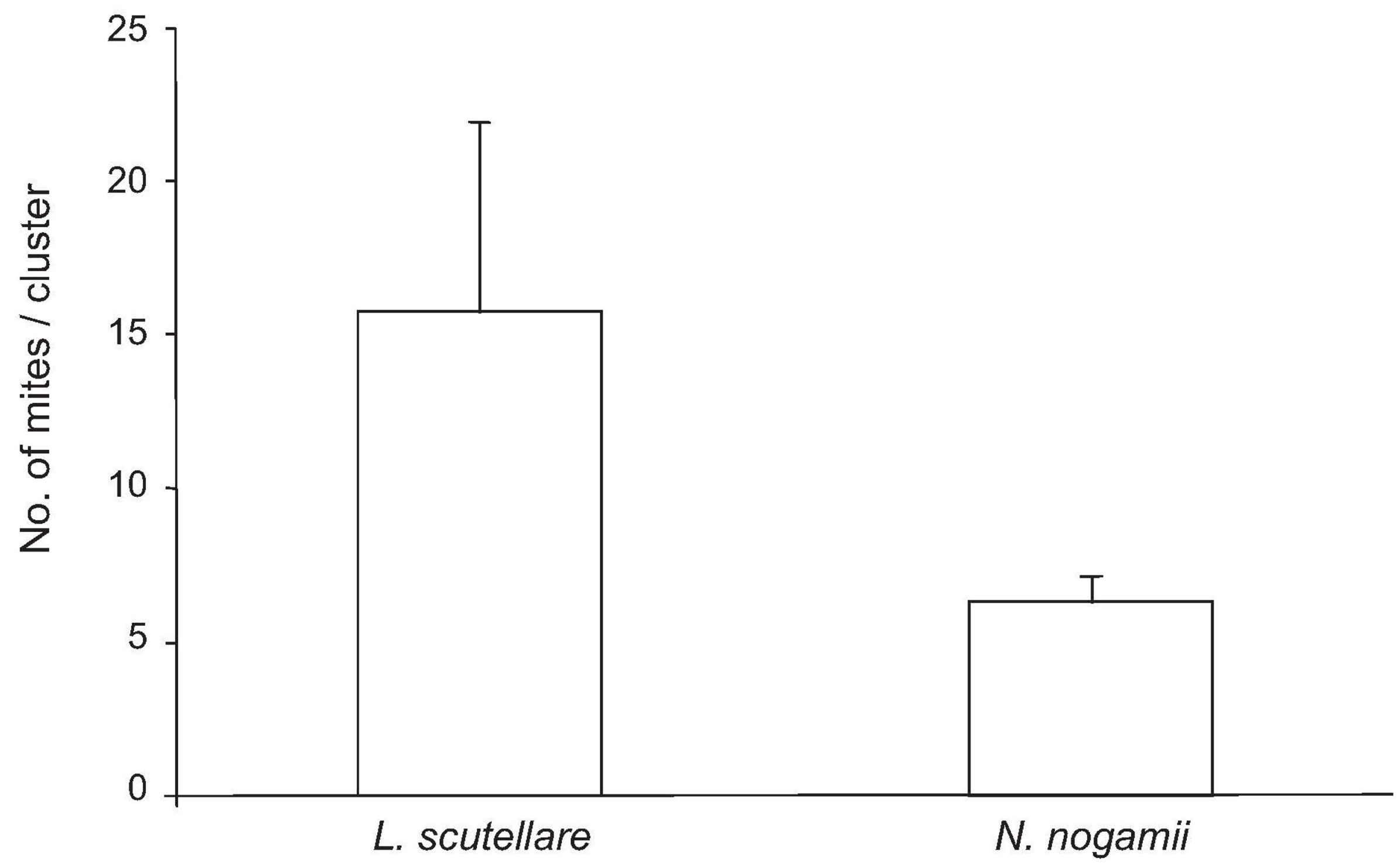


Fig. 8.

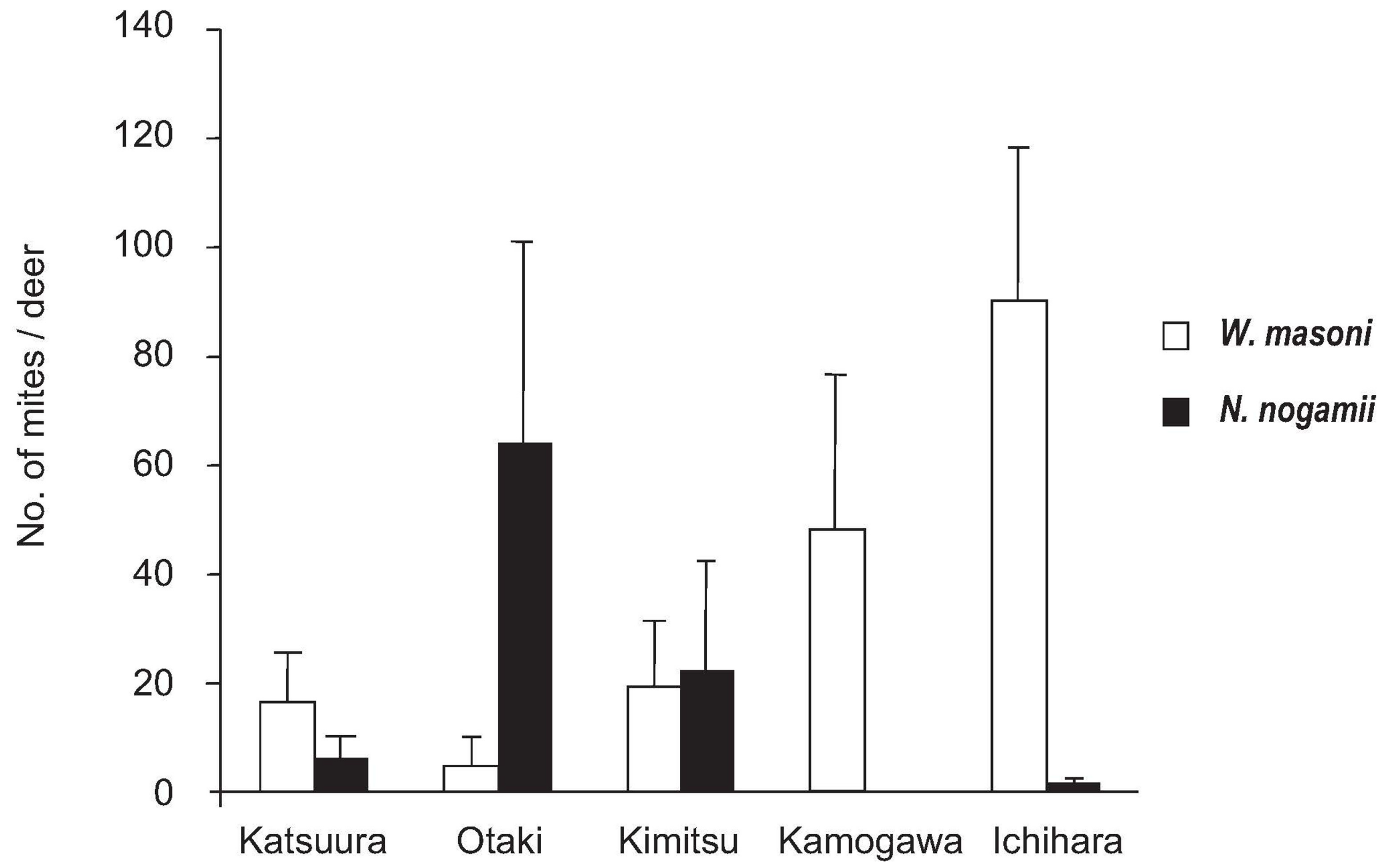

